\title{
Bacteriophage M13 as a Scaffold for Preparing Conductive Polymeric Composite Fibers
}

\author{
Zhongwei Niu', Michael A. Bruckman¹, Brandon Harp ${ }^{1}$, Charlene M. Mello ${ }^{2}(\bowtie)$, and Qian Wang $(\bowtie)$ \\ ${ }^{1}$ Department of Chemistry and Biochemistry and Nanocenter, University of South Carolina, Columbia, SC 29208, USA \\ ${ }^{2}$ Bioscience and Technology Team, US Army Natick Soldier Research, Development \& Engineering Center, Natick, MA 01760-5020, USA \\ Received: 23 May 2008/ Revised: 29 July 2008/Accepted: 30 July 2008 \\ CTsinghua Press and Springer-Verlag 2008. This article is published with open access at Springerlink.com
}

\begin{abstract}
Using biological templates to build one-dimensional functional materials holds great promise in developing nanosized electrical devices, sensors, catalysts, and energy storage units. In this communication, we report a versatile assembly process for the preparation of water-soluble conductive polyaniline (PANi)/M13 composite nanowires by employing the bacteriophage M13 as a template. The surface lysine residues of M13 can be derivatized with carboxylic groups to improve its binding ability to the aniline; the resulting modified M13 is denoted as m-M13. Highly negatively-charged poly(sulfonated styrene) was used both as a dopant acid and a stabilizing agent to enhance the stability of the composite fibers in aqueous solution. A transparent solution of the conductive PANi/m-M13 composite fibers can be readily obtained without any further purification step. The fibers can be easily fabricated into thin conductive films due to their high aspect ratio and good solubility in aqueous solution. This synthesis discloses a unique and versatile way of using bionanorods to produce composite fibrillar materials with narrow dispersity, high aspect ratio, and high processibility, which may have many potential applications in electronics, optics, sensing, and biomedical engineering.
\end{abstract}

\section{KEYWORDS}

Bacteriophage M13, nanofiber, conductive polymer, self-assembly, bioconjugation

The controlled growth and fabrication of onedimensional (1-D) nanostructured objects such as fibers, tubes, and rods, is an emerging research area due to their potential applications in developing nanosized electric devices, sensors, catalysts, and energy storage units [1-4]. In particular, employing biological building blocks as templates in 1-D materials synthesis holds great promise for future research directions [5-8]. Among the wide variety of biological scaffolds, viruses and viral-like particles have recently attracted much attention for the development of novel biocomposite materials. Rod-like biomacromolecular assemblies, such as the tobacco mosaic virus (TMV) and M13 bacteriophage, have well-defined structural features, high aspect ratio, narrow size distribution, and good water solubility [9-16]. They are stable and can endure treatment over a wide range of $\mathrm{pH}$ values and temperatures, and with organic solvents (such as 50\% methanol [17] and 30\% DMSO [18]). Moreover, the surface functionalities and properties of these bionanorods can be manipulated either by traditional bioconjugation methods or genetic engineering

Address correspondence to Charlene M. Mello, Charlene.Mello@us.army.mil; Qian Wang,wang@mail.chem.sc.edu 
without disrupting their integrity [19-22]. Due to these properties, TMV and M13 are particularly interesting scaffolds for developing 1-D functional materials [10, 14, 23].

Previously we have shown that by using TMV as the template, 1-D polyaniline/TMV composite nanowires can be prepared by a head-to-tail selfassembly process of TMV $[13,14]$. Polyaniline (PANi) is a conducting polymer that has been extensively studied for optical and electronic applications [24-28]. A 1-D nanostructured PANi would be a promising candidate for the development of nanosized electronic devices, sensors, energy storage devices, and other devices [26, 29-31]. Although many approaches to produce electronically active 1-D materials have been developed [32-34], realization of 1-D nanostructured conducting PANi with controllable morphologies and sizes, especially with good dispersity, is still a great challenge. We report here a versatile assembly process for the preparation of water-soluble conductive PANi/M13 composite nanowires by employing the bacteriophage M13 as a template.

M13 is a cylindrical protein capsid consisting of 2700 identical major coat proteins as well as several minor coat proteins surrounding a single-stranded DNA genome. The rod-like M13 is $880 \mathrm{~nm}$ in length and $6.6 \mathrm{~nm}$ in diameter and one of the most studied rod-like viruses for developing new biocomposite materials [35]. Compared to the native TMV, a rod-like plant virus with a length of $300 \mathrm{~nm}$ and a diameter of $18 \mathrm{~nm}$, the advantages of M13 are that it has a smaller diameter and higher aspect ratio, readily forms anisotropic thin films and is much more pliable than TMV in solution. Thus, with M13 as a template, it should be possible to prepare more elastic composite fibers with smaller diameter, and better processability. Figure 1 shows a schematic illustration of the preparation of composite fibers and a corresponding conductive thin film of the PANi/M13 composite. We report here that conductive PANi/M13 composite nanowires can be readily obtained by incubation of M13 with poly(sulfonated styrene) (PSS) and ammonium persulfate (APS).

Unmodified M13 was first used as the template to prepare PANi/M13 composite fibers; however, we found that it was difficult to control the morphology of the final composite fibers due to the low surface charge of $\mathrm{M} 13$ at the reaction $\mathrm{pH}$ of 4 . To address this, the lysine group on the outer surface of native M13 (Figs. 2(a), (b)) was derivatized to a carboxylate group by a simple bioconjugation with glutaric anhydride (Fig. 1) in order to introduce more negative charges on the surface of M13 and improve the binding of aniline. After reaction for $12 \mathrm{~h}$ with a large excess of glutaric anhydride, the modified M13 (m-M13) was purified by dialysis, precipitation, and re-suspension in fresh buffer. MALDI-MS analysis of the protein P8 showed the molecular mass of the unmodified M13 subunit was $5241 \mathrm{~m} / \mathrm{z}$ (Fig. 2(c)). The mass of the modified product indicates that the majority of the protein subunits are mono-derivatized with acid groups $(5355 \mathrm{~m} / \mathrm{z})$. Weak peaks at $5241 \mathrm{~m} / \mathrm{z}$ and 5470 $\mathrm{m} / \mathrm{z}$ are also present (Fig. 2(c)), which can be assigned to unmodified and dual-modified protein subunits, respectively. The integrity of the m-M13 was

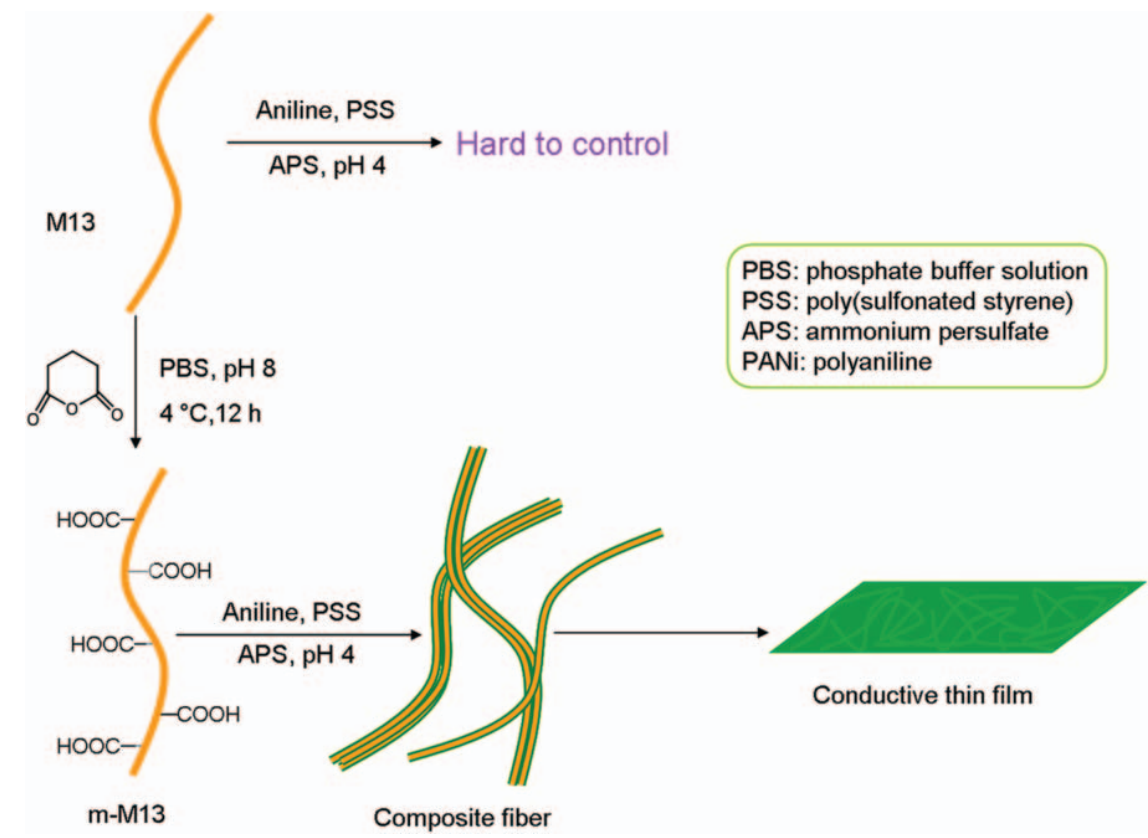

Figure 1 Schematic illustration of the preparation of PSS-PANi/M13 composite fibers and conductive thin films 


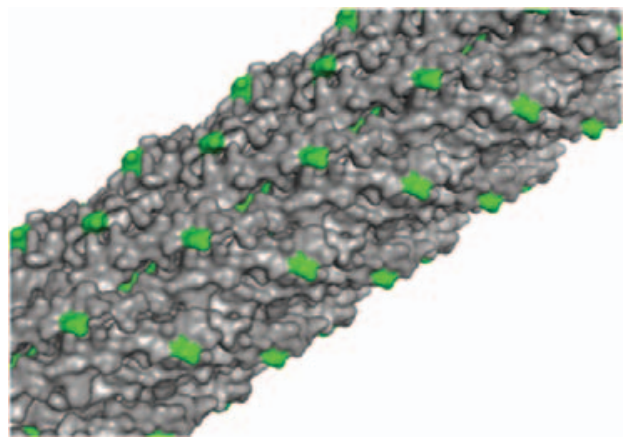

(a)

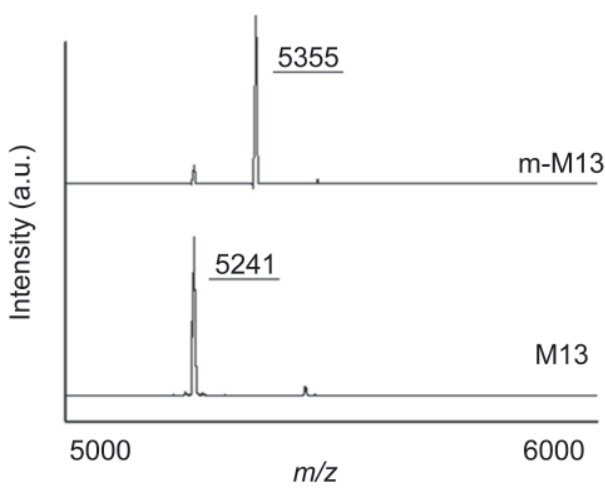

(c)

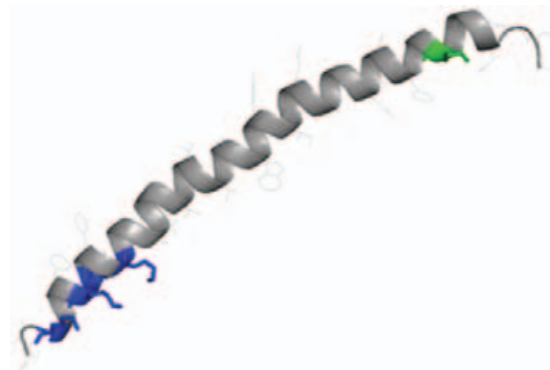

(b)

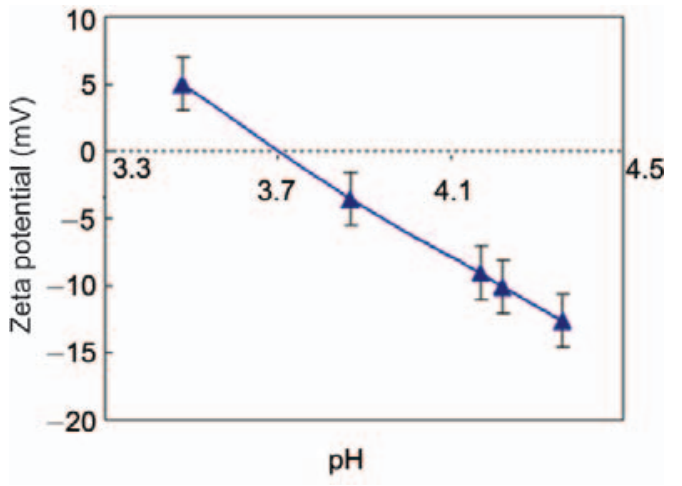

(d)

Figure 2 (a) Helical organization of M13 major coat proteins P8. (b) A single subunit structure of coat protein P8 is presented as ribbon diagram with lysines being highlighted, of which Lys-8 (in green) is easily accessible and the other 4 lysines (in blue) are buried in the coat protein. (c) MALDI-TOF MS of the coat protein P8 of unmodified M13 $(5241 \mathrm{~m} / \mathrm{z}$ ) and the modified $\mathrm{m}-\mathrm{M} 13$ indicating a single modification $(5355 \mathrm{~m} / \mathrm{z})$ of subunits. Weak peaks at $5241 \mathrm{~m} / \mathrm{z}$ and $5470 \mathrm{~m} / \mathrm{z}$ can be assigned to the unmodified and dual-modified protein subunits. (d) Zeta potential of acid modified m-M13 at different $\mathrm{pH}$

confirmed by both atomic force microscopy (AFM) (not shown) and transmission electron microscopy (TEM) analysis (Fig. 3(a)). After modification, zeta potential measurements were used to determine the surface charge and isoelectric point (pI) of m-M13. As shown in Fig. 2(d), after modification, the pI was estimated to be 3.7 as compared with a $\mathrm{pI}$ of 4.3 for native M13 [10]. As shown in Fig. 2(b), there are five lysines (in blue and green colors) in the major coat protein P8 of M13, but, based on the crystal structure, only lysine-8 is exposed to the exterior environment (Fig. 2(a)). We postulate that the majority of the modifications take place at lysine-8. Detailed reactivity and proteomics studies are still ongoing and will be reported elsewhere.

With modified M13 as template, a series of experiments were conducted with the reaction conditions shown in Table 1. In a typical synthesis, the m-M13 was incubated with aniline for $24 \mathrm{~h}$ at room temperature using APS as the oxidant and PSS as the stabilizer. The $\mathrm{pH}$ of the solution was adjusted to around 4.0 with dilute aq. $\mathrm{HCl}$ and aq. $\mathrm{NaOH}$. The final composite fiber was purified through precipitation using polyethylene glycol (PEG)/ NaCl and re-suspension in nanopure water. Addition of highly charged PSS leads to a dramatic improvement in the stability of the composite fibers in aqueous

Table 1 Reaction conditions for m-M13 templated synthesis of polyaniline composite nanowires at $\mathrm{pH} 4$ for $24 \mathrm{~h}$

\begin{tabular}{ccccl}
\hline $\begin{array}{c}\mathrm{m}-\mathrm{M} 13 \\
(\mathrm{mg} / \mathrm{mL})\end{array}$ & $\begin{array}{c}\text { Aniline } \\
(\mu \mathrm{L} / \mathrm{mL})\end{array}$ & $\begin{array}{c}\mathrm{PSS} \\
(\mathrm{mg} / \mathrm{mL})\end{array}$ & $\begin{array}{c}\text { APS } \\
(\mathrm{mg} / \mathrm{mL})\end{array}$ & \multicolumn{1}{c}{ Resulting fibers } \\
\hline 0.1 & 0.2 & 0.4 & 0.5 & $\begin{array}{l}\text { Single PANi/m-M13 } \\
\text { fiber }\end{array}$ \\
0.2 & 0.4 & 0.8 & 1 & $\begin{array}{l}\text { Bundled PANi/m-M13 } \\
\text { fibers with diameter } \\
\sim 25 \mathrm{~nm}\end{array}$ \\
0.5 & 1 & 2 & 2.5 & $\begin{array}{l}\text { Bundled PANi/m-M13 } \\
\text { fibers with diameter } \\
\sim 50 \mathrm{~nm}\end{array}$ \\
\hline
\end{tabular}




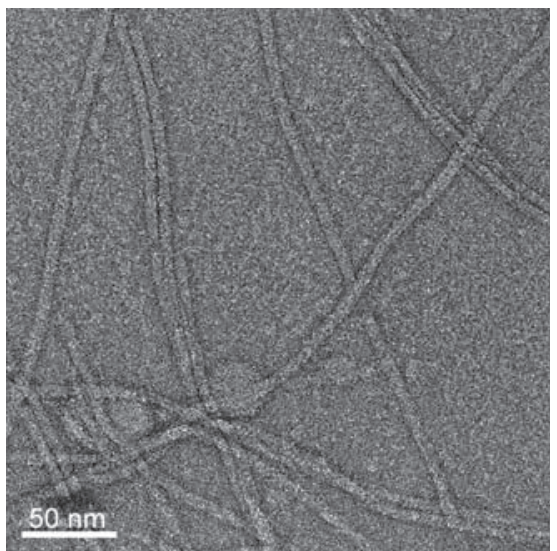

(a)

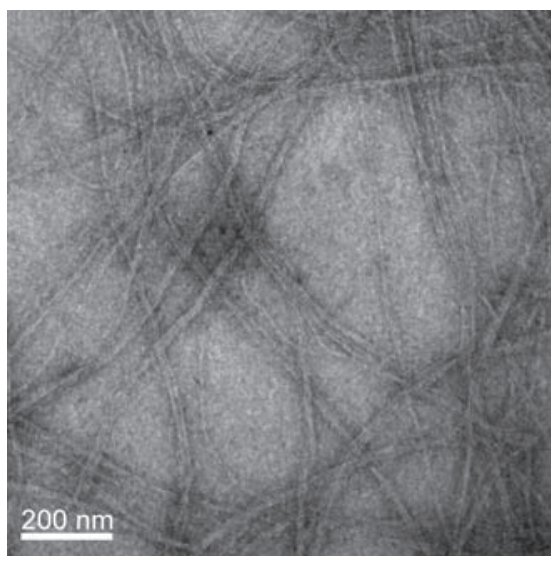

(c)

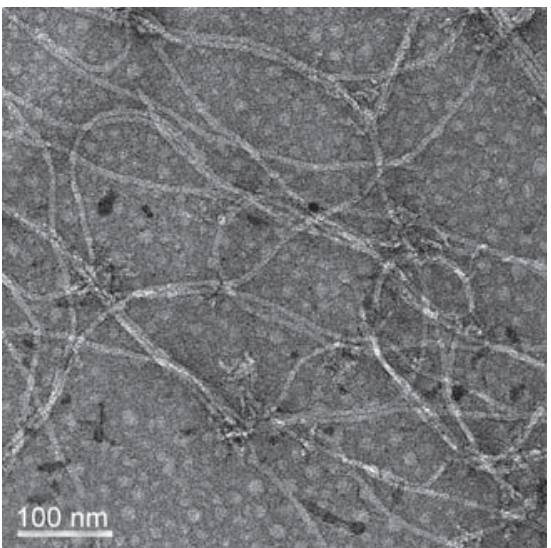

(b)

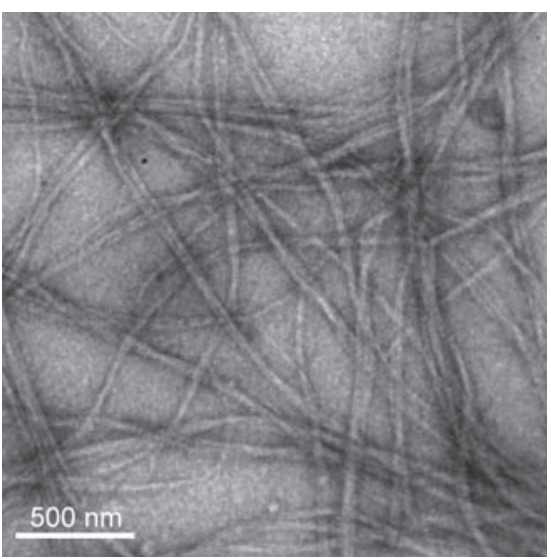

(d)
Figure 3 TEM images of $\mathrm{m}-\mathrm{M} 13$ (a) and PANi/m-M13 composite fibers obtained with initial concentrations of $\mathrm{m}-\mathrm{M} 13$ of $0.1 \mathrm{mg} / \mathrm{mL}$ (b), $0.2 \mathrm{mg} / \mathrm{mL}$ (c), and $0.5 \mathrm{mg} / \mathrm{mL}$ (d)

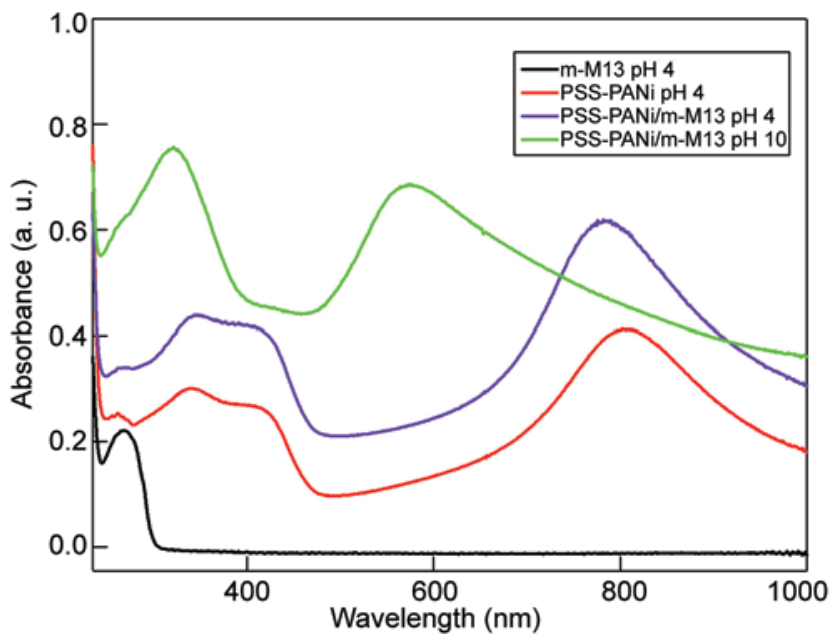

Figure 4 UV-vis spectra of m-M13 and PANi/m-M13 composite fibers

solution and was found to be crucial for the success of the synthesis [36]. In addition, PSS served as an acidic dopant to enhance the conductivity of PANi $[27,28]$.

As shown in Fig. 3(a), upon modification, m-M13 retains the same diameter of $6.6 \mathrm{~nm}$ as the native M13. With lower concentrations of $\mathrm{m}-\mathrm{M} 13$ as the template, single polyaniline/m-M13 fibers can be readily prepared which preserve the high aspect ratio of M13 (Fig. 3(b)). The diameter of the composite wires increased to $\sim 8 \mathrm{~nm}$ when the concentration of m-M13 was increased to $0.1 \mathrm{mg} / \mathrm{mL}$. Furthermore, small bundle-like structures, composed of several single small fibers with a total diameter around $25 \mathrm{~nm}$, were formed with increased m-M13 concentration (Fig. 3(c)). The bundle size was increased to $50 \mathrm{~nm}$ when the concentration of m-M13 was $0.5 \mathrm{mg} / \mathrm{mL}$ (Fig. 3(d)).

As shown in Fig. 4, the UV-vis spectrum of the m-M13 has a peak at $269 \mathrm{~nm}$ which is similar to that observed for the native M13. The red curve represents a control experiment with PSS/PANi reacted at pH 4 without adding m-M13. The PSS/PANi possesses the polyaniline signature absorbance peak around $420 \mathrm{~nm}$. The polaron band in the $790 \mathrm{~nm}$ region confirms the presence of PANi in the conducting form. For the PSS-PANi/m-M13 composite(purple curve), a spectrum similar to that of the PSS/PANi control experiment was observed with the inclusion of a small peak at $269 \mathrm{~nm}$ which can be attributed to the contribution from m-M13. As the $\mathrm{pH}$ of the solution was increased from 4 to 10 , the PANi peak at $420 \mathrm{~nm}$ decreased in intensity and the polaron band around $790 \mathrm{~nm}$ disappeared (green curve). The strong absorption peak at ca. $570 \mathrm{~nm}$ suggests that, at $\mathrm{pH}$ 10, PANi has been completely de-doped to the base form. These results are comparable to those previously observed for both chemically and enzymatically synthesized PANi [27, 28, 30, 37].

To study the electrical conductivity, the composite fibers were coated on a glass wafer $(\rho=10 \Omega \cdot \mathrm{cm})$ by casting $200 \mu \mathrm{L}$ of a $0.2 \mathrm{mg} / \mathrm{mL}$ composite fiber solution and drying overnight at room temperature. 
Composite fiber conductivity was determined to be $5 \times 10^{-4} \mathrm{~S} / \mathrm{cm}$ using a standard four-point probe technique. The conductivity is similar to literature reports where PSS was used as the doping agent $[27,28]$. The PSS-PANi/m-M13 composite fibers could be easily fabricated into thin films via a spincoating process (Fig. 5). The homogenous thin film showed a sensitive response towards $\mathrm{pH}$ change. As shown in Fig. 5, when the thin film was exposed to gaseous $\mathrm{NH}_{3}$, the color of the thin film changed from dark green to dark blue in $1 \mathrm{~min}$. Upon exposure to gaseous $\mathrm{HCl}$, the color of the thin film reverted to dark green. These color changes were fully reversible and could be repeated multiple times.

In conclusion, the surface lysine residues of M13 can be derivatized with carboxylic groups to improve its binding ability to aniline. Highly negatively charged PSS can be used both as a dopant acid and a stabilizing agent to enhance the stability of the composite fibers in aqueous solution. A transparent solution of the conductive PANi/m-M13 composite fibers can be readily obtained without any further purification step. The fibers can be easily fabricated into thin conductive films due to their high aspect ratio and good solubility in aqueous solution. This synthesis discloses a unique and versatile way of using bionanorods to produce composite fibrillar materials with narrow dispersity, high aspect ratio,

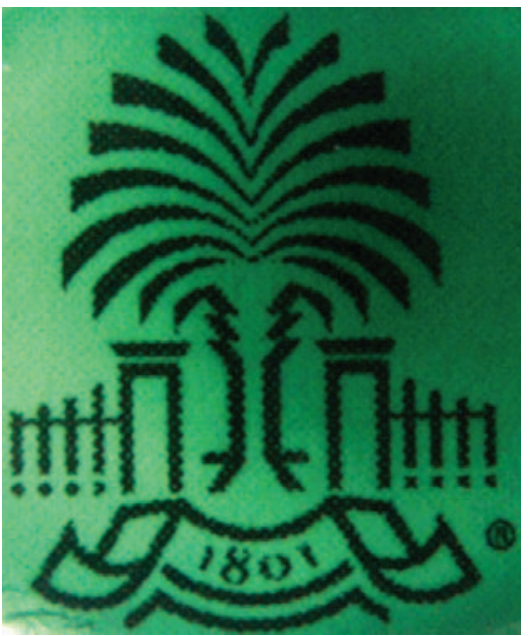

(a)

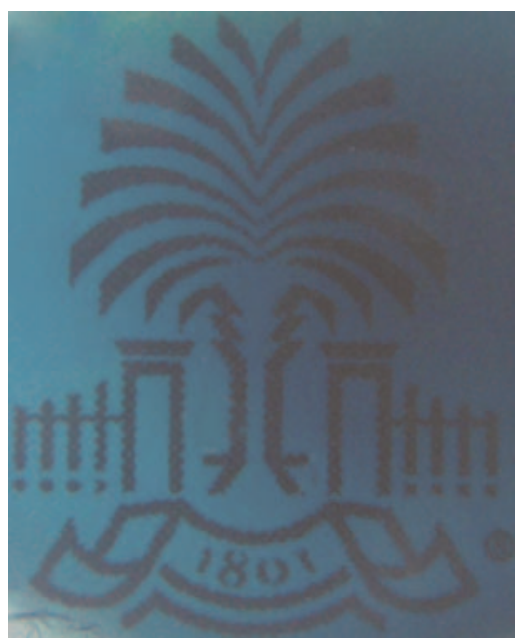

(b)
Figure 5 Optical images of PSS-PANi/m-M13 composite thin film on a glass slide under acidic conditions (a) and basic conditions (b) showing clear green and blue colors, although the central regions are too intense to see the real colors. The thin film is transparent and the Univ. South Carolina logo can be seen clearly through the film and high processibility, which may have many potential applications in electronics [10, 38], optics [39], sensing, and biomedical engineering [40].

\section{Experimental}

Large scale amplification of M13. M13 virus was grown and purified following standard biochemical protocols. Briefly, a $1 \mathrm{~L}$ of an E. coli ER2738 culture was grown in LB-tet media to mid-log phase and infected with $1 \mathrm{~mL}$ of wild-type M13 bacteriophage $\left(10^{12} \mathrm{PFU} /\right.$ $\mathrm{mL}$ ). The culture was incubated at $37^{\circ} \mathrm{C}$ with shaking for 5-6 h, centrifuged to remove bacterial cells, the virus collected by PEG- NaCl (20\% PEG and 2.5 $\mathrm{mol} / \mathrm{L} \mathrm{NaCl}$ ) precipitation and reconstituted in Trisbuffer. The typical yield was $30 \mathrm{mg}$ of M13 per liter of infected bacteria suspension. The concentration was determined spectrophotometrically using an extinction coefficient of $3.84 \mathrm{~cm}^{2} / \mathrm{mg}$ at $269 \mathrm{~nm}$ [41].

Surface modification of M13. In a typical synthesis, a stock solution of M13 $(20 \mathrm{mg} / \mathrm{mL}, 1 \mathrm{~mL})$ in $150 \mathrm{mmol} / \mathrm{L}$ Tris- $\mathrm{HCl}$ buffer was dialyzed with $0.01 \mathrm{~mol} / \mathrm{L} \mathrm{pH} 7.8$ phosphate buffer. After dialysis, the stock solution was diluted to $1 \mathrm{mg} / \mathrm{mL}$ with a $0.01 \mathrm{~mol} / \mathrm{L} \mathrm{pH} 7.8$ phosphate buffer. To this solution, glutaric anhydride was directly added. The reaction mixture was placed at $4{ }^{\circ} \mathrm{C}$ overnight. PEG$\mathrm{NaCl}$ solution was subsequently used to pellet the M13 virus followed by re-suspension overnight in $0.01 \mathrm{~mol} / \mathrm{L} \mathrm{pH} 7.8$ phosphate buffer.

Synthesis of PSS-PANi/m-M13 composites. In a typical synthesis, distilled aniline, poly(sulfonated styrene) and ammonium persulfate were added to a solution of m-M13 (Table 1). The $\mathrm{pH}$ of the solution was adjusted with aq. $\mathrm{HCl}(0.01 \mathrm{~mol} / \mathrm{L})$ and aq. $\mathrm{NaOH}$ $(0.01 \mathrm{~mol} / \mathrm{L})$ to 4.0 . The reaction mixture was incubated at room temperature for $24 \mathrm{~h}$ before it was pelleted with PEG $-\mathrm{NaCl}$. The pellet was collected and resuspended in nanopure water to obtain the PSS-PNAi/m-M13 composite nanofiber suspension. This operation was normally repeated three times in 
order to completely remove the dissolved PANi.

Preparation of samples for TEM analysis. A solution of composite nanofiber solution $(20 \mu \mathrm{L})$ was deposited onto a 300-mesh carbon-coated copper grid for $2 \mathrm{~min}$. The grid was then stained with $2 \%$ uranyl acetate before TEM analysis.

MALDI-TOF MS of M13 subunit. A solution of M13 $(1 \mathrm{mg} / \mathrm{mL}, 26 \mu \mathrm{L})$ was treated with guanidinium$\mathrm{HCl}(6.0 \mathrm{~mol} / \mathrm{L}, 4 \mu \mathrm{L})$ for $5 \mathrm{~min}$ at room temperature. The denatured protein was spotted onto a MALDI plate using Millipore ZipTip ${ }_{\mu-\mathrm{C} 18}{ }^{\circledR}$ tips to remove the salts. The samples were analyzed using a Bruker Ultra-Flex I TOF/TOF mass spectrometer with MS grade sinapinic acid in $70 \%$ acetonitrile and $0.1 \%$ TFA as the matrix.

\section{Acknowledgements}

We acknowledge Dr. Lynne Samuelson for her kind and extremely helpful suggestions. We are grateful for financial support from NSF-DMR-0706431, NSF career award, US DoD, and the W. M. Keck Foundation. This manuscript has been approved by the U.S. Army Natick Soldier Research, Development and Engineering Center for unlimited distribution (PAO\# 08-107).

\section{References}

[1] Cui, Y.; Wei, Q. Q.; Park, H. K.; Lieber, C. M. Nanowire nanosensors for highly sensitive and selective detection of biological and chemical species. Science 2001, 293, 1289-1292.

[2] Yang, C.; Zhong, Z. H.; Lieber, C. M. Encoding electronic properties by synthesis of axial modulation-doped silicon nanowires. Science 2005, 310, 1304-1307.

[3] Hopkins, D. S.; Pekker, D.; Goldbart, P. M.; Bezryadin, A. Quantum interference device made by DNA templating of superconducting nanowires. Science 2005, 308, 1762-1765.

[4] Ferry, D. K. Materials science: Nanowires in nanoelectronics. Science 2008, 319, 579-580.

[5] Ellis-Behnke, R. G.; Liang, Y. X.; You, S. W.; Tay, D. K. C.; Zhang, S. G.; So, K. F.; Schneider, G. E. Nano neuro knitting: Peptide nanofiber scaffold for brain repair and axon regeneration with functional return of vision. Proc.
Natl. Acad. Sci. U.S.A. 2006, 103, 5054-5059.

[6] Mershin, A.; Cook, B.; Kaiser, L.; Zhang, S. G. A classic assembly of nanobiomaterials. Nat. Biotechnol. 2005, 23, 1379-1380.

[7] Sargeant, T. D.; Guler, M. O.; Oppenheimer, S. M.; Mata, A.; Satcher, R. L.; Dunand, D. C.; Stupp, S. I. Hybrid bone implants: Self-assembly of peptide amphiphile nanofibers within porous titanium. Biomaterials 2008, 29, 161-171.

[8] Jiang, H. Z.; Guler, M. O.; Stupp, S. I. The internal structure of self-assembled peptide amphiphiles nanofibers. Soft Matter. 2007, 3, 454-462.

[9] Fonoberov, V. A.; Balandin, A. A. Low-frequency vibrational modes of viruses used for nanoelectronic selfassemblies. Phys. Status Solidi B 2004, 241, R67-R69.

[10] Nam, K. T.; Kim, D. W.; Yoo, P. J.; Chiang, C. Y.; Meethong, N.; Hammond, P. T.; Chiang, Y. M.; Belcher, A. M. Virus-enabled synthesis and assembly of nanowires for lithium ion battery electrodes. Science 2006, 312, 885-888.

[11] Mao, C. B.; Solis, D. J.; Reiss, B. D.; Kottmann, S. T.; Sweeney, R. Y.; Hayhurst, A.; Georgiou, G.; Iverson, B.; Belcher, A. M. Virus-based genetic toolkit for the directed synthesis of magnetic and semiconducting nanowires. Science 2004, 303, 213-217.

[12] Lee, S. W.; Mao, C. B.; Flynn, C. E.; Belcher, A. M. Ordering of quantum dots using genetically engineered viruses. Science 2002, 296, 892-895.

[13] Niu, Z. W.; Bruckman, M.; Kotakadi, V. S.; He, J.; Emrick, T.; Russell, T. P.; Yang, L.; Wang, Q. Study and characterization of tobacco mosaic virus head-to-tail assembly assisted by aniline polymerization. Chem. Commun. 2006, 3019-3021.

[14] Niu, Z. W.; Bruckman, M. A.; Li, S. Q.; Lee, L. A.; Lee, B.; Pingali, S. V.; Thiyagarajan, P.; Wang, Q. Assembly of tobacco mosaic virus into fibrous and macroscopic bundled arrays mediated by surface aniline polymerization. Langmuir 2007, 23, 6719-6724.

[15] Tseng, R. J.; Baker, C. O.; Shedd, B.; Huang, J. X.; Kaner, R. B.; Ouyang, J. Y.; Yang, Y. Charge transfer effect in the polyaniline-gold nanoparticle memory system. Appl. Phys. Lett. 2007, 90, 053101.

[16] Fonoberov, V. A.; Balandin, A. A. Phonon confinement effects in hybrid virus-inorganic nanotubes for nanoelectronic applications. Nano Lett. 2005, 5, 19201923.

[17] Royston, E.; Lee, S. Y.; Culver, J. N.; Harris, M. T. 
Characterization of silica-coated tobacco mosaic virus. J. Colloid Interface Sci. 2006, 298, 706-712.

[18] Bruckman, M. A.; Kaur, G.; Lee, L. A.; Xie, F.; Sepulveda, J.; Breitenkamp, R.; Zhang, X. F.; Joralemon, M.; Russell, T. P.; Emrick, T.; Wang, Q. Surface modification of tobacco mosaic virus with "click" chemistry. Chembiochem. 2008, 9, 519-523.

[19] Wang, Q.; Lin, T. W.; Tang, L.; Johnson, J. E.; Finn, M. $\mathrm{G}$. Icosahedral virus particles as addressable nanoscale building blocks. Angew. Chem., Int. Ed. 2002, 41, 459462.

[20] Wang, Q.; Lin, T. W.; Johnson, J. E.; Finn, M. G. Natural supramolecular building blocks: Cysteine-added mutants of cowpea mosaic virus. Chem. Biol. 2002, 9, 813-819.

[21] Wang, Q.; Chan, T. R.; Hilgraf, R.; Fokin, V. V.; Sharpless, K. B.; Finn, M. G. Bioconjugation by copper(I)-catalyzed azide-alkyne [3+2] cycloaddition. J. Am. Chem. Soc. 2003, 125, 3192-3193.

[22] Schlick, T. L.; Ding, Z. B.; Kovacs, E. W.; Francis, M. B. Dual-surface modification of the tobacco mosaic virus. J. Am. Chem. Soc. 2005, 127, 3718-3823.

[23] Chiang, C. Y.; Mello, C. M.; Gu, J. J.; Silva, E. C. C. M.; van Vliet, K. J.; Belcher, A. M. Weaving genetically engineered functionality into mechanically robust virus fibers. Adv. Mater. 2007, 19, 826-832.

[24] Rezai, T.; Bock, J. E.; Zhou, M. V.; Kalyanaraman, C.; Lokey, R. S.; Jacobson, M. P. Conformational flexibility, internal hydrogen bonding, and passive membrane permeability: Successful in silico prediction of the relative permeabilities of cyclic peptides. J. Am. Chem. Soc. 2006, 128, 14073-14080.

[25] MacDiarmid, A. G. Synthetic metals: A novel role for organic polymers. Syn. Met. 2001, 125, 11-22.

[26] Huang, J. X.; Kaner, R. B. The intrinsic nanofibrillar morphology of polyaniline. Chem. Commun. 2006, 367376.

[27] Liu, W.; Cholli, A. L.; Nagarajan, R.; Kumar, J.; Tripathy, S.; Bruno, F. F.; Samuelson, L. The role of template in the enzymatic synthesis of conducting polyaniline. J. Am. Chem. Soc. 1999, 121, 11345-11355.

[28] Liu, W.; Kumar, J.; Tripathy, S.; Senecal, K. J.; Samuelson, L. Enzymatically synthesized conducting polyaniline. J. Am. Chem. Soc. 1999, 121, 71-78.

[29] Zhang, D. H.; Wang, Y. Y. Synthesis and applications of one-dimensional nano-structured polyaniline: An overview. Mater. Sci. Eng. B 2006, 134, 9-19.

[30] Zhang, X.; Goux, W. J.; Manohar, S. K. Synthesis of polyaniline nanofibers by "nanofiber seeding". J. Am. Chem. Soc. 2004, 126, 4502-4503.

[31] Chiou, N. R.; Epstein, A. J. Polyaniline nanofibers prepared by dilute polymerization. Adv. Mater. 2005, 17, 1679-1683.

[32] Sun, X.; Hagner, M. Novel poly(acrylic acid)mediated formation of composited, poly(3,4ethylenedioxythiophene)-based conducting polymer nanowires. Macromolecules 2007, 40, 8537-8539.

[33] Tseng, R. J.; Huang, J. X.; Ouyang, J. Y.; Kaner, R. $B$.; Yang, Y. Polyaniline nanofiber/gold nanoparticle nonvolatile memory. Nano Lett. 2005, 5, 1077-1080.

[34] Huang, J. X.; Kaner, R. B. A general chemical route to polyaniline nanofibers. J. Am. Chem. Soc. 2004, 126, 851-855.

[35] Lee, S. W.; Belcher, A. M. Virus-based fabrication of micro- and nanofibers using electrospinning. Nano Lett. 2004, 4, 387-390.

[36] Niu, Z.; Liu, J.; Lee, L. A.; Bruckman, M. A.; Zhao, D.; Koley, G.; Wang, Q. Biological templated synthesis of water-soluble conductive polymeric nanowires. Nano Lett. 2007, 7, 3729-3733.

[37] Thiyagarajan, M.; Samuelson, L. A.; Kumar, J.; Cholli, A. L. Helical conformational specificity of enzymatically synthesized water-soluble conducting polyaniline nanocomposites. J. Am. Chem. Soc. 2003, 125, 1150211503.

[38] Yoo, P. J.; Nam, K. T.; Qi, J. F.; Lee, S. K.; Park, J.; Belcher, A. M.; Hammond, P. T. Spontaneous assembly of viruses on multilayered polymer surfaces. Nat. Mater. 2006, 5, 234-240.

[39] Prasad, T.; Turner, M.; Falkner, J.; Mittlernan, D.; Johnson, J.; Lin, T. W.; Colvin, V. Nanostructured virus crystals for X-ray optics. IEEE T. Nanotechnol. 2006, 5, 93-96.

[40] Lin, Y.; Su, Z.; Niu, Z.; Li, S.; Kaur, G.; Lee, L. A.; Wang, Q. Layer-by-layer assembly of viral capsid for cell adhesion. Acta Biomater. 2008, 4, 838-843.

[41] Maguire, J. F.; McTague, J. P.; Rondelez, F. Rotational diffusion of sterically interacting rodlike macromolecules. Phys. Rev. Lett. 1980, 45, 1891-1894. 